\title{
HOXC11 positively regulates the long non-coding RNA HOTAIR and is associated with poor prognosis in colon adenocarcinoma
}

\author{
NANA GONG ${ }^{1 *}$, FEI LI ${ }^{2 *}$, YANAN WANG ${ }^{1 *}$, ZIZI LI $^{3}$, WANQIU WANG ${ }^{1}$, \\ TINGTING GONG ${ }^{4}$, XIAOJUN MENG ${ }^{5}$ and HONGTAO CHEN ${ }^{1}$
}

\author{
Departments of ${ }^{1}$ Laboratory Medicine, ${ }^{2}$ Pharmacy, ${ }^{3}$ Pathology, ${ }^{4}$ Ultrasound and ${ }^{5}$ Endocrinology, \\ The Fifth Affiliated Hospital of Sun Yat-Sen University, Zhuhai, Guangdong 519000, P.R. China
}

Received May 15, 2020; Accepted February 22, 2021

DOI: $10.3892 / \mathrm{etm} .2021 .10745$

\begin{abstract}
Colorectal cancer ranks third in terms of incidence and second in terms of mortality worldwide. The homeobox transcript antisense intergenic RNA (HOTAIR), which was found to be located on the antisense chain of the homeobox $\mathrm{C}$ (HOXC) gene cluster, is a long non-coding RNA involved in multiple types of tumors. The role of HOXC11 in tumors remains unclear. Reverse transcription-quantitative PCR was performed to detect the expression level of HOXC11 in colon adenocarcinoma. Cell proliferation and invasion were assessed. RNase protection assay was used to test the possibility of RNA duplex formation. The increased expression and co-expression trend of HOXC11 and HOTAIR were identified in multiple types of cancer from The Cancer Genome Atlas and the results were validated in 12 colon adenocarcinoma and paired non-tumor tissue samples. The expression of HOXC11 and HOTAIR was found to be associated with poor prognosis in colon adenocarcinoma and kidney renal clear cell carcinoma. Furthermore, HOXC11 was found to positively regulate HOTAIR by RNA duplex formation and promoted the proliferation and invasion of colon adenocarcinoma cells.
\end{abstract}

Correspondence to: Dr Hongtao Chen, Department of Laboratory Medicine, The Fifth Affiliated Hospital of Sun Yat-Sen University, 52 Meihua Dong Road, Xiangzhou, Zhuhai, Guangdong 519000, P.R. China

E-mail: 13926925941@139.com

Dr Xiaojun Meng, Department of Endocrinology, The Fifth Affiliated Hospital of Sun Yat-Sen University, 52 Meihua Dong Road, Xiangzhou, Zhuhai, Guangdong 519000, P.R. China

E-mail: 13926925941@139.com

${ }^{*}$ Contributed equally

Key words: colon adenocarcinoma, antisense chain of the homeobox C 11, homeobox transcript antisense intergenic RNA, survival

\section{Introduction}

In total, $>1.8$ million new colorectal cancer cases and 881,000 deaths are estimated to have occurred in 2018, accounting for $\sim 1$ in 10 cancer cases and deaths worldwide (1). Colorectal cancer ranks third in incidence and second in mortality globally, and poses a serious threat to human health, particularly in certain European countries (e.g., Hungary, Slovenia, Slovakia, The Netherlands and Norway), Australia/New Zealand, Northern America and Eastern Asia (including Japan, the Republic of Korea and Singapore) (1). The currently approved therapeutic approaches to colon adenocarcinoma include surgery, radiofrequency ablation, chemotherapy, radiation therapy, cryosurgery and targeted therapy (2).

Long non-coding RNAs (lncRNAs), a class of RNAs $>200$ nt long and lacking protein-coding ability, have emerged to play key roles in numerous biological processes, such as differentiation, development, cellular address codes and oncogenesis (3-5). The homeobox transcript antisense intergenic RNA (HOTAIR) is a well-known long non-coding RNA that functions as an oncogene $(6,7)$. Abnormal expression of HOTAIR has been reported in multiple cancers, and may lead to abnormal cell differentiation and proliferation, invasion and metastasis (8-11).

Located in chromosome 12 (q13.13), homeobox C11 (HOXC11) belongs to the homeobox family of genes, which encode a highly conserved family of transcription factors that play key roles in embryonic implantation, evolution and morphogenesis in all multicellular organisms (12-14). Disorders of HOXC11 may lead to abnormal embryonal development, endometriosis and infertility $(14,15)$. HOTAIR was reported to regulate the expression of homeobox genes and is located in the antisense chain of HOXC11, where an overlapping region between HOTAIR and HOXC11 has been identified (16). Thus, the present study was undertaken to explore the interaction between HOTAIR and HOXC11. Data from The Cancer Genome Atlas (TCGA) database were analyzed, and a co-expression trend was found between the IncRNA HOTAIR and the transcription factor HOXC11 in several types of cancer, such as colon adenocarcinoma, esophageal carcinoma, breast cancer and kidney renal clear cell carcinoma, among others. Therefore, assays with colon adenocarcinoma cells and tissues were performed to identify the interaction between HOTAIR and HOXC11 and their functions in colon adenocarcinoma. 


\section{Materials and methods}

Cell cultures. The SW480 and HCT116 colon cancer cell lines were purchased from the Shanghai Institute of Cell Biology (Shanghai, China). SW480 cells were cultured in Leibovitz's L-15 Medium (Gibco; Thermo Fisher Scientific, Inc.) supplemented with 10\% FBS (Gibco; Thermo Fisher Scientific, Inc.) at $37^{\circ} \mathrm{C}$ in a humidified atmosphere containing $5 \% \mathrm{CO}_{2}$. HCT116 cells were cultured in DMEM (Gibco; Thermo Fisher Scientific, Inc.) supplemented with 10\% FBS (Gibco; Thermo Fisher Scientific, Inc.) at $37^{\circ} \mathrm{C}$ in a humidified atmosphere containing $5 \% \mathrm{CO}_{2}$.

Specimens. A total of 12 paired colon carcinoma and adjacent normal tissue samples were obtained from the Fifth Affiliated Hospital of Sun Yat-sen University (Zhuhai, China) between 18th February and 6th December 2018. All patients were diagnosed with primary colon carcinoma. Ethics approval (approval no. K206-1) was obtained from the Research Ethics Committee of the Fifth Affiliated Hospital of Sun Yat-sen University. Informed consent for their tissues to be used for research purposes was obtained from all patients prior to performing this study.

Bioinformatics analysis. The gene expression data of colon carcinoma, esophageal carcinoma, breast cancer and kidney renal clear cell carcinoma were obtained from TCGA website (https://cancergenome.nih.gov/). Kaplan-Meier analysis was plotted by UALCAN (17). Overlapping region was found between HOXC11 and HOTAIR by UCSC genome browser (a ssembly ID, hg38) (18).

Transfection. HOXC11 knockdown lentivirus [pSLenti-U 6-shRNA(HOXC11)-CMV-EGFP-F2A-Puro-WPRE] and negative control (NC) lentivirus (pSLenti-U6-CMV-EGF P-F2A-Puro-WPRE) were obtained from Shanghai OBIO Technology (Shanghai) Corp., Ltd. SW480 and HCT116 cells were transfected with lentiviruses at a multiplicity of infection (MOI) of 10 in the presence of $4 \mu \mathrm{g} / \mathrm{ml}$ puromycin. After 1 week of puromycin screening, SW480 and HCT116 cells were used for subsequent experimentation. Transfection of the HOXC11 plasmid [pcDNA3.1(+)] was performed according to the protocol of Lipofectamine ${ }^{\circledR} 3000$ Reagent (Invitrogen; Thermo Fisher Scientific, Inc.). In total, $1 \mu \mathrm{g}$ HOXC11 or negative control plasmid, $2 \mu 1 \mathrm{P} 3000^{\mathrm{TM}}$ Reagent, and $1.5 \mu \mathrm{l}$ Lipofectamine $^{\mathrm{TM}} 3000$ Reagent were added to $50 \mu \mathrm{l}$ Opti-MEM medium per $1 \times 10^{5}$ cells. The medium was changed after $6 \mathrm{~h}$ and the transfection effect was detected after 2 days.

RNase protection assay. The composition of the RNase digestion mixture for RNase protection assay (RPA) was as follows: $10 \mathrm{mM}$ Tris- $\mathrm{HCl}$ ( $\mathrm{pH} 7.5$ ), $300 \mathrm{mM} \mathrm{NaCl}, 5 \mathrm{mM}$ EDTA (pH 7.5), and $20 \mu \mathrm{l}$ of RNase A/T1 Mix per $1 \mathrm{ml}$ of reaction mixture. RNase A/T1 can digest single-stranded RNAs, but not RNA duplexes. The RNA samples were incubated at $37^{\circ} \mathrm{C}$ for 60 min prior to treatment with an RNAse A+T cocktail (Sigma-Aldrich; Merck KGaA). Subsequently, the samples were incubated at $37^{\circ} \mathrm{C}$ for $30 \mathrm{~min}$ after the addition of the RNAse cocktail, and treated with proteinase $\mathrm{K}$, as previously described (19). The RNA used in the RPA was extracted from SW480 and HCT116 cells.
RT-qPCR analysis. Total RNA from SW480 and HCT116 cells was isolated with TRIzol ${ }^{\circledR}$ reagent (Invitrogen; Thermo Fisher Scientific, Inc.) according to the manufacturer's protocol. Fast All-in-One RT Kit (cat. no. ES-RT001; Shanghai Yishan Biotechnology, Co., Ltd.; https://www.esunbio.com/search-1--/ u0072/u0074/u0030/u0030/u0031.html) was used to perform the reverse transcription using the temperature protocol of $42^{\circ} \mathrm{C}$ for 15 min. GoTaq ${ }^{\circledR}$ qPCR Master Mix A6001 (cat. no. A6001; Promega Corporation) was used to perform qPCR. The thermocycling conditions included an initial denaturation step $\left(95^{\circ} \mathrm{C}\right.$, $2 \mathrm{~min}$ ), followed by 40 cycles of $95^{\circ} \mathrm{C}$ for $15 \mathrm{sec}$ and $60^{\circ} \mathrm{C}$ for $1 \mathrm{~min}$. The primer sequences used were as follows: HOXC11 forward, 5'-GCTACTCCTCCTGCTATGC-3' and reverse, 5'-GACGCTGTTCTTGTTGACTG-3'; HOTAIR forward, 5'-GCCAAGCACCTCTATCTC-3' and reverse, 5'-GACACTG AACGGACTCTG-3' and GAPDH forward, 5'-AGAAGGCT GGGGCTCATTTG-3' and reverse, 5'-AGGGGCCATCCACA GTCTTC-3' The relative expression level of mRNAs was normalized to GAPDH and was calculated using the $2^{-\Delta \Delta C q}$ method (20).

MTT assay. The cells were inoculated into 96-well plates at a concentration of 2,000 cells per $100 \mu \mathrm{l}$ at $37^{\circ} \mathrm{C}$ with $5 \% \mathrm{CO}_{2}$ overnight. After incubation for $4 \mathrm{~h}$ at $37^{\circ} \mathrm{C}$ with $5 \% \mathrm{CO}_{2}, 50 \mu \mathrm{l}$ 1X MTT reagent (Nanjing KeyGen Biotech Co.,Ltd.) and $150 \mu \mathrm{l}$ DMSO were added to well. The mixture was shaken well and the absorbance was detected at $490 \mathrm{~nm}$ using the SpectraMax ${ }^{\circledR}$ 340PC38 spectrophotometer (Molecular Devices, LLC).

Statistical analysis. Statistical analyses were performed by SPSS 20.0 (IBM Corp.). Graphs were generated by GraphPad Prism 7 (GraphPad Software, Inc.). $\mathrm{P}<0.05$ from a two-tailed test was considered to indicate statistically significant difference. Unpaired student's t-test was used to evaluate the differences between two groups of independent samples. Data are presented as mean $\pm \mathrm{SD}$. All the results were repeated $\geq$ three times.

\section{Results}

HOXC11 and HOTAIR expression is increased in multiple types of cancer. After analyzing the data of colon adenocarcinoma, esophageal carcinoma, breast cancer and kidney renal clear cell carcinoma, which were downloaded from TCGA, it was observed that both HOXC11 and HOTAIR were significantly upregulated in the tumor groups compared with the normal groups (Fig. S1). Similar expression trends were observed between HOXC11 and HOTAIR. In addition, RT-qPCR assay was performed to detect the expression of HOXC11 and HOTAIR in 12 paired colon adenocarcinoma and adjacent normal tissue samples. It was determined that HOTAIR and HOXC11 were upregulated in the majority of colon adenocarcinoma tissues, which was consistent with the results of TCGA database (Fig. 1A and B).

Co-expression of HOXC11 and HOTAIR. A co-expression trend was observed between HOXC11 and HOTAIR in colon adenocarcinoma $(r=0.797)$, esophageal carcinoma $(r=0.838)$, breast cancer $(\mathrm{r}=0.922)$ and kidney renal clear cell carcinoma $(\mathrm{r}=0.719)$, with statistically significant differences (supplementary Fig. S2A-D). Similar results were obtained from 

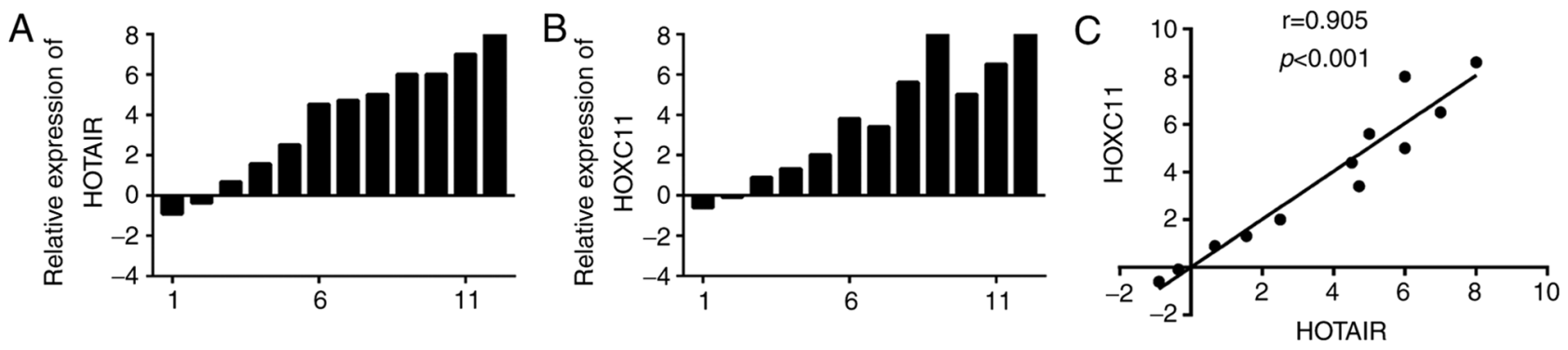

Figure 1. Increased expression of HOTAIR and HOXC11 in colon adenocarcinoma tissues. (A) Increased expression of (A) HOTAIR and (B) HOXC11 was observed in 10 of 12 colon adenocarcinoma tissues compared with the paired non-tumor tissues. (C) Co-expression of HOTAIR and HOXC11. HOTAIR, homeobox transcript antisense intergenic RNA; HOXC11, homeobox C11.
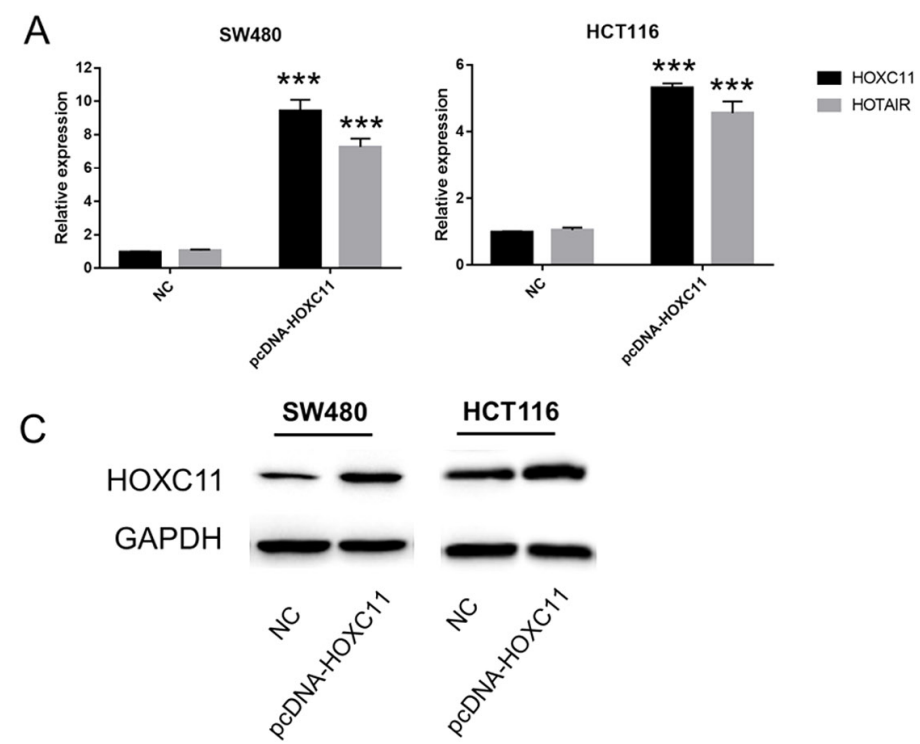

$\mathrm{E}$

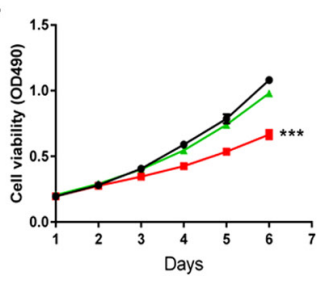

SW480

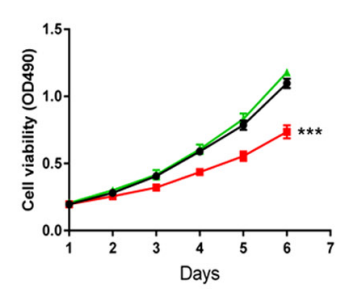

HCT116
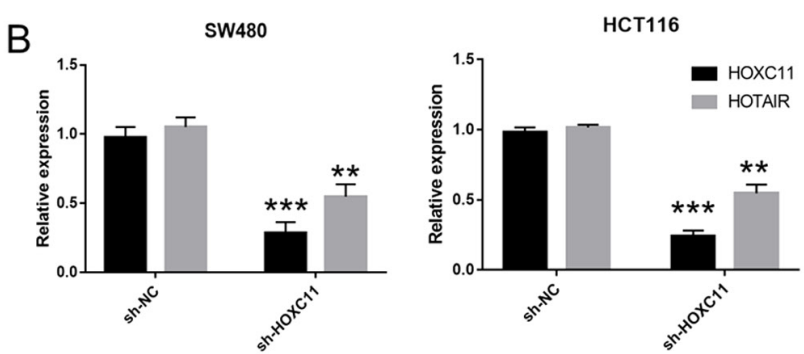

D
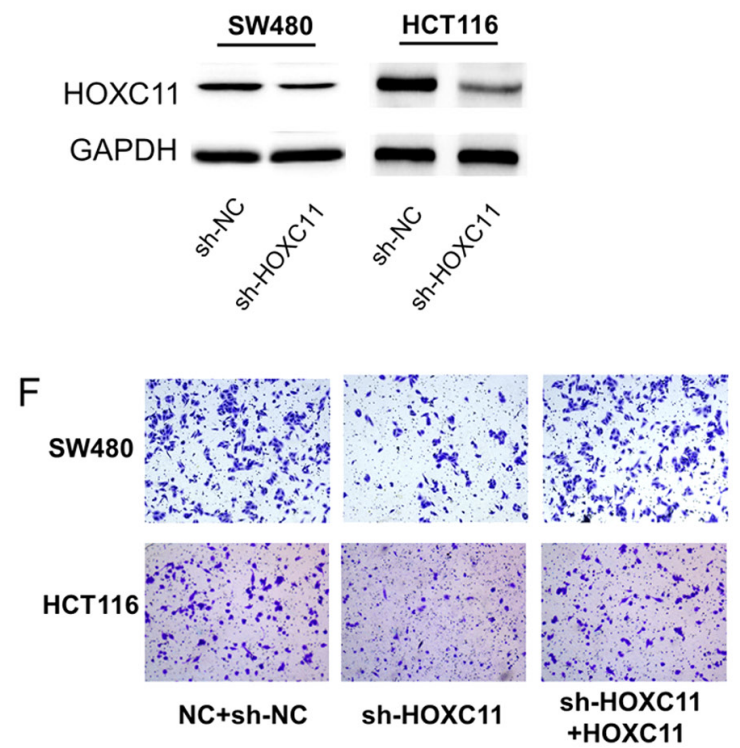

Figure 2. Reduced expression of HOXC11 inhibits the proliferation and invasion ability of colon adenocarcinoma SW480 and HCT116 cells. (A) HOXC11 overexpression was shown to upregulate the expression of HOTAIR. (B) Knocking down HOXC11 inhibited the expression of HOTAIR. (C and D) Protein levels of HOXC11 after overexpression and knockdown. (E) Cell proliferation was assessed following HOXC11 knockdown and overexpression in SW480 and HCT116 cells. (F) Invasion ability was inhibited in cells with HOXC11 knockdown and was rescued after overexpressing HOXC11 (magnification, x100). ${ }^{* * *} \mathrm{P}<0.001,{ }^{* *} \mathrm{P}<0.01$. HOTAIR, homeobox transcript antisense intergenic RNA; HOXC11, homeobox C11; NC, group transfected with negative control plasmid; sh-NC, group infected with negative control lentivirus.

colon adenocarcinoma and adjacent normal tissues $(\mathrm{r}=0.905$, $\mathrm{P}<0.001$; Fig. 1C).

HOXC11 and HOTAIR expression is associated with poor prognosis. Higher HOXC11 expression was associated with poorer prognosis in colon adenocarcinoma $(\mathrm{P}=0.02)$ and kidney renal clear cell carcinoma $(\mathrm{P}=0.006)$, but not in esophageal carcinoma $(\mathrm{P}=0.26)$ and breast cancer $(\mathrm{P}=0.28$; supplementary Fig. S3A-D). Higher expression of HOTAIR was associated with poorer prognosis in colon adenocarcinoma $(\mathrm{P}=0.021)$, breast cancer $(\mathrm{P}=0.047)$ and kidney renal clear cell carcinoma
$(\mathrm{P}<0.001)$, but there was no statistically significant difference in the prognosis of esophageal carcinoma by HOTAIR expression $(\mathrm{P}=0.11$; supplementary Fig. S3E-H).

Decreased expression of HOXC11 inhibits the proliferation and invasion of colon adenocarcinoma cells. After knocking down and overexpressing HOXC11 in SW480 cells and HCT116 cells, it was found that the expression level of HOTAIR was modified with the changes in the expression of HOXC11 (Fig. 2A-D). Furthermore, decreased expression of HOXC11 inhibited the ability of proliferation and invasion 
A HOXC11
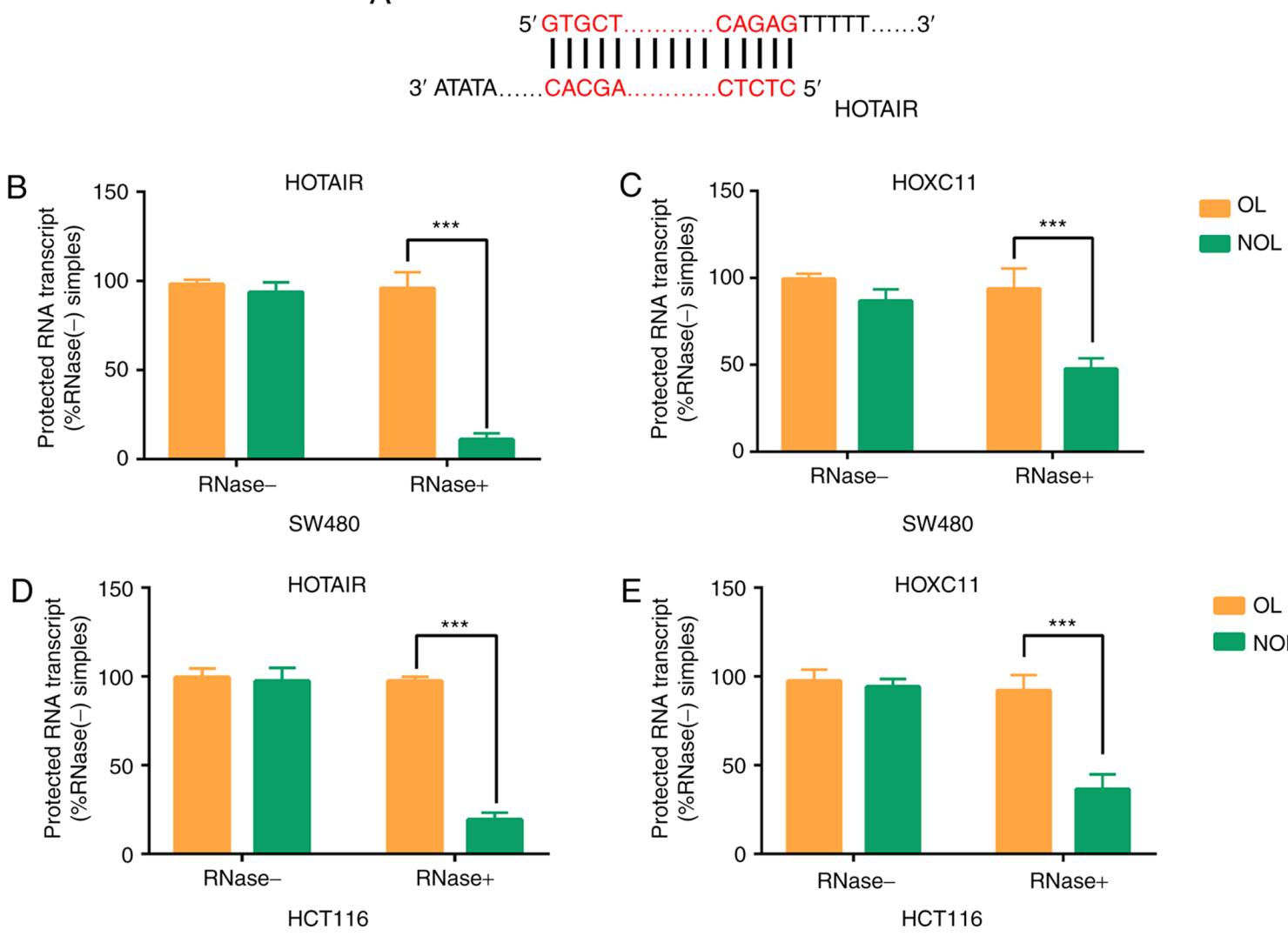

Figure 3. Overlapping region of HOXC11 and HOTAIR transcript is protected from degradation by RNase A+T, suggesting the formation of an RNA duplex. (A) Overlapping region between HOXC11 and HOTAIR. (B and C) Results of the RPA showed that non-overlapping regions of HOTAIR andHOXC11 were degraded by RNAse A+T in SW480 cells. (D and E) Results of the RPA showed that non-overlapping regions of HOTAIR and HOXC11were degraded by RNAse A+T in HCT116 cells. ${ }^{* * *} \mathrm{P}<0.001$. OL, overlapping. NOL, non-overlapping; HOTAIR, homeobox transcript antisense intergenic RNA; HOXC11, homeobox C11; RPA, RNase protection assay.

of colon adenocarcinoma cells, whereas these effects were rescued by $\mathrm{HOXC11}$ overexpression (Fig. 2E and F).

HOXC11 formed RNA duplex and increased HOTAIR expression. To explore the interaction between HOXC11 and HOTAIR, HOXC11 was overexpressed and knocked down in SW480 and HCT116 cells. It was found that HOTAIR expression changed significantly with the changes in HOXC11 expression. According to UCSC genome browser, an overlapping region was found between HOXC11 and HOTAIR (Fig. 3A). The results of the RPA showed that non-overlapping regions were degraded after adding RNAse A+T, which can digest single-stranded RNAs but not RNA duplexes (Fig. 3B-E). Accordingly, RNA duplex formation between HOXC11 and HOTAIR was observed.

\section{Discussion}

In the present study, it was observed that HOXC11 expression is increased in colon adenocarcinoma and may positively regulate HOTAIR by forming an RNA duplex. The expression of HOXC11 and HOTAIR has been associated with poor prognosis in multiple types of cancer $(9,21,22)$.

HOXC11 belongs to the homeobox gene family, which encodes a highly conserved family of transcription factors that play key roles in embryo implantation, evolution and morphogenesis in all multicellular organisms (23-26). In recent years, there has been an increasing number of studies indicating that HOX family genes are involved in the occurrence and progression of several malignancies, such as gastric cancer, Wilms' tumor and acute myeloid leukemia $(27,28)$. HOXC11 is reported to be involved in gene fusion, which could promote abnormal gene expression and drive leukemogenesis (29,30). HOXC11 was considered to play an important role in early intestinal development during embryonic growth (31). Consistent with the present study, it was found that the expression of HOXC11 was significantly increased in multiple cancers, such as colon adenocarcinoma, esophageal carcinoma, breast cancer and kidney renal clear cell carcinoma. Furthermore, increased HOXC11 was associated with poor outcome in colon adenocarcinoma and kidney renal clear cell carcinoma, indicating that $\mathrm{HOXC11}$ may participate in the development of these cancers.

In recent years, IncRNAs have been reported to play important roles in numerous biological processes, such as development, differentiation, immunity, Alzheimer's disease, cardiovascular disease and tumors $(32,33)$. HOTAIR has been extensively investigated and was reported to participate in multiple tumors. Serum HOTAIR was considered to be a diagnostic biomarker for esophageal squamous cell carcinoma (34). HOTAIR may also promote the occurrence and development of renal cell carcinoma (7). Özeş et al (35) observed that HOTAIR 
was implicated in the DNA damage response, cellular senescence and chemoresistance. Xue et al (36) reported that HOTAIR enhances estrogen receptor signaling and confers tamoxifen resistance in breast cancer. After analyzing the data of multiple cancers from TCGA, the authors of the present study found that HOTAIR was upregulated in colon adenocarcinoma, esophageal carcinoma, breast cancer and kidney renal clear cell carcinoma, and was associated with poor prognostic in most types of cancer. Although HOTAIR was reported to regulate $\mathrm{HOX}$ gene expression, there has been no reported research, to the authors' knowledge, on HOX genes regulating HOTAIR expression (37). The present study was the first to identify that HOXC11 could positively regulate HOTAIR by forming an RNA duplex within the overlapping region.

In summary, it was herein found and validated that the transcription factor HOXC11 and the IncRNA HOTAIR were upregulated in colon carcinoma. In addition, the decreased expression of HOXC11 may inhibit the proliferation and invasion ability of colon adenocarcinoma cells. Furthermore, HOXC11 may positively regulate HOTAIR by forming the RNA duplex. The findings of the present study may expand our current understanding of the functions of HOX genes and HOTAIR. Moreover, the expression of HOXC11 and HOTAIR may be considered as a potential biomarker and therapeutic target against colon carcinoma. However, as the main aim of the present study was to study the association between HOXC11 and HOTAIR, experiments in vivo were not conducted. Therefore, the effects of HOXC11 on survival should be validated in in vivo experiments in the future.

\section{Acknowledgements}

Not applicable.

\section{Funding}

No funding was received.

\section{Availability of materials and data}

The datasets used and/or analyzed during the current study are available from the corresponding author on reasonable request.

\section{Authors' contributions}

NG participated in manuscript preparation and performed the experiments. FL and YNW performed literature search and the collection of gene expression and survival data from TCGA and UALCAN. WQW, ZZL and TTG performed data analysis. HTC and XJM participated in research design and performed manuscript review. NG and HTC confirm the authenticity of all the raw data. All authors read and approved the final manuscript.

\section{Ethics approval and consent to participate}

Ethics approval (approval no. K206-1) was obtained from the Research Ethics Committee of the Fifth Affiliated Hospital of Sun Yat-sen University. Informed consent was obtained from all patients.

\section{Patient consent for publication}

Not applicable.

\section{Competing interests}

The authors declare that they have no competing interests.

\section{References}

1. Bray F, Ferlay J, Soerjomataram I, Siegel RL, Torre LA and Jemal A: Global cancer statistics 2018: GLOBOCAN estimates of incidence and mortality worldwide for 36 cancers in 185 countries. CA Cancer J Clin 68: 394-424, 2018.

2. Williams C, DiLeo A, Niv Y and Gustafsson JA: Estrogen receptor beta as target for colorectal cancer prevention. Cancer Lett 372: 48-56, 2016.

3. Batista PJ and Chang HY: Long noncoding RNAs: Cellular address codes in development and disease. Cell 152: 1298-1307, 2013.

4. He Y, Meng XM, Huang C, Wu BM, Zhang L, Lv XW and Li J: Long noncoding RNAs: Novel insights into hepatocelluar carcinoma. Cancer Lett 344: 20-27, 2014.

5. Fatica A and Bozzoni I: Long non-coding RNAs: New players in cell differentiation and development. Nat Rev Genet 15: 7-21, 2014.

6. Kalwa M, Hänzelmann S, Otto S, Kuo CC, Franzen J, Joussen S, Fernandez-Rebollo E, Rath B, Koch C, Hofmann A, et al: The lncRNA HOTAIR impacts on mesenchymal stem cells via triple helix formation. Nucleic Acids Res 44: 10631-10643, 2016.

7. Hong Q, Li O, Zheng W, Xiao WZ, Zhang L, Wu D, Cai GY, He JC and Chen XM: LncRNA HOTAIR regulates HIF-1 $\alpha / A X L$ signaling through inhibition of miR-217 in renal cell carcinoma. Cell Death Dis 8: e2772, 2017.

8. Fu WM, Zhu X, Wang WM, Lu YF, Hu BG, Wang H, Liang WC, Wang SS, Ko CH, Waye MM, et al: Hotair mediates hepatocarcinogenesis through suppressing miRNA-218 expression and activating P14 and P16 signaling. J Hepatol 63: 886-895, 2015.

9. Gupta RA, Shah N, Wang KC, Kim J, Horlings HM, Wong DJ, Tsai MC, Hung T, Argani P, Rinn JL, et al: Long non-coding RNA HOTAIR reprograms chromatin state to promote cancer metastasis. Nature 464: 1071-1076, 2010.

10. Zhang A, Zhao JC, Kim J, Fong KW, Yang YA, Chakravarti D, Mo YY and Yu J: LncRNA HOTAIR enhances the androgen-receptor-mediated transcriptional program and drives castration-resistant prostate cancer. Cell Rep 13: 209-221, 2015.

11. Heubach J, Monsior J, Deenen R, Niegisch G, Szarvas T, Niedworok C, Schulz WA and Hoffmann MJ: The long noncoding RNA HOTAIR has tissue and cell type-dependent effects on HOX gene expression and phenotype of urothelial cancer cells. Mol Cancer 14: 108, 2015.

12. Nnamani MC, Ganguly S, Erkenbrack EM, Lynch VJ, Mizoue LS, Tong Y, Darling HL, Fuxreiter M, Meiler J and Wagner GP: A derived allosteric switch underlies the evolution of conditional cooperativity between HOXA11 and FOXO1. Cell Rep 15: 2097-2108, 2016.

13. Roumengous S, Rousset R and Noselli S: Polycomb and Hox genes control JNK-induced remodeling of the segment boundary during Drosophila morphogenesis. Cell Rep 19: 60-71, 2017.

14. Kherdjemil Y,Lalonde RL, Sheth R, Dumouchel A, de Martino G, Pineault KM, Wellik DM, Stadler HS, Akimenko MA and Kmita M: Evolution of Hoxa11 regulation in vertebrates is linked to the pentadactyl state. Nature 539: 89-92, 2016.

15. Zanatta A, Rocha AM, Carvalho FM, Pereira RM, Taylor HS, Motta EL, Baracat EC and Serafini PC: The role of the Hoxa10/HOXA10 gene in the etiology of endometriosis and its related infertility: A review. J Assist Reprod Genet 27: 701-710, 2010.

16. Amândio AR, Necsulea A, Joye E, Mascrez B and Duboule D: hotair is dispensible for mouse development. PLoS Genet 12: e1006232, 2016.

17. Chandrashekar DS, Bashel B, Balasubramanya SA, Creighton CJ, Ponce-Rodriguez I, Chakravarthi BV and Varambally S: UALCAN: A Portal for Facilitating Tumor Subgroup Gene Expression and Survival Analyses. Neoplasia 19: 649-658, 2017.

18. Kent WJ, Sugnet CW, Furey TS, Roskin KM, Pringle TH, Zahler AM and Haussler D: The human genome browser at UCSC. Genome Res 12: 996-1006, 2002. 
19. Faghihi MA, Modarresi F, Khalil AM, Wood DE, Sahagan BG, Morgan TE, Finch CE, St Laurent G III, Kenny PJ and Wahlestedt C: Expression of a noncoding RNA is elevated in Alzheimer's disease and drives rapid feed-forward regulation of beta-secretase. Nat Med 14: 723-730, 2008.

20. Livak KJ and Schmittgen TD: Analysis of relative gene expression data using real-time quantitative PCR and the 2(-Delta Delta C(T)) method. Methods 25: 402-408, 2001.

21. Ali A, Creevey L, Hao Y, McCartan D, O'Gaora P, Hill A, Young L and McIlroy M: Prosaposin activates the androgen receptor and potentiates resistance to endocrine treatment in breast cancer. Breast Cancer Res 17: 123, 2015.

22. Loewen G, Jayawickramarajah J, Zhuo Y and Shan B: Functions of lncRNA HOTAIR in lung cancer. J Hematol Oncol 7: 90, 2014.

23. Bhatlekar S, Fields JZ and Boman BM: HOX genes and their role in the development of human cancers. J Mol Med (Berl) 92 811-823, 2014

24. Bhatlekar S, Fields JZ and Boman BM: Role of HOX genes in stem cell differentiation and cancer. Stem Cells Int 2018: 3569493,2018

25. Du H and Taylor HS: The role of Hox genes in female reproductive tract development, adult function, and fertility. Cold Spring Harb Perspect Med 6: a023002, 2015.

26. Luo Z, Rhie SK, Lay FD and Farnham PJ: A Prostate cancer risk element functions as a repressive loop that regulates HOXA13. Cell Rep 21: 1411-1417, 2017.

27. Zhu H, Dai W, Li J, Xiang L, Wu X, Tang W, Chen Y, Yang Q, Liu M, Xiao Y, et al: HOXD9 promotes the growth, invasion and metastasis of gastric cancer cells by transcriptional activation of RUFY3. J Exp Clin Cancer Res 38: 412, 2019.

28. Luo H, Wang F, Zha J, Li H, Yan B, Du Q, Yang F, Sobh A, Vulpe C, Drusbosky L, et al: CTCF boundary remodels chromatin domain and drives aberrant HOX gene transcription in acute myeloid leukemia. Blood 132: 837-848, 2018.
29. Taketani T, Taki T, Shibuya N, Kikuchi A, Hanada R and Hayashi Y: Novel NUP98-HOXC11 fusion gene resulted from a chromosomal break within exon 1 of HOXC11 in acute myeloid leukemia with $\mathrm{t}(11 ; 12)(\mathrm{p} 15 ; \mathrm{q} 13)$. Cancer Res 62: 4571-4574, 2002.

30. Gu BW, Wang Q, Wang JM, Xue YQ, Fang J, Wong KF, Chen B, Shi ZZ, Shi JY, Bai XT, et al: Major form of NUP98/HOXC11 fusion in adult AML with $\mathrm{t}(11 ; 12)(\mathrm{p} 15 ; \mathrm{q} 13)$ translocation exhibits aberrant trans-regulatory activity. Leukemia 17: 1858-1864, 2003.

31. Mitchelmore C, Troelsen JT, Sjöström H and Norén O: The HOXC11 homeodomain proteininteracts withthelactase-phlorizin hydrolase promoter and stimulates HNF1alpha-dependent transcription. J Biol Chem 273: 13297-13306, 1998.

32. Zhang Y and Cao X: Long noncoding RNAs in innate immunity. Cell Mol Immunol 13: 138-147, 2016.

33. Idda ML, Munk R, Abdelmohsen K and Gorospe M: Noncoding RNAs in Alzheimer's disease. Wiley Interdiscip Rev RNA 9: 9, 2018.

34. Wang W, He X, Zheng Z, Ma X, Hu X, Wu D and Wang M: Serum HOTAIR as a novel diagnostic biomarker for esophageal squamous cell carcinoma. Mol Cancer 16: 75, 2017.

35. Özeş AR, Miller DF, Özeş ON, Fang F, Liu Y, Matei D, Huang T and Nephew KP: NF- $\kappa B-H O T A I R$ axis links DNA damage response, chemoresistance and cellular senescence in ovarian cancer. Oncogene 35: 5350-5361, 2016.

36. Xue X, Yang YA, Zhang A, Fong KW, Kim J, Song B, Li S, Zhao JC and Yu J: LncRNA HOTAIR enhances ER signaling and confers tamoxifen resistance in breast cancer. Oncogene 35: 2746-2755, 2016

37. Woo CJ and Kingston RE: HOTAIR lifts noncoding RNAs to new levels. Cell 129: 1257-1259, 2007.

(i) $\Theta$ This work is licensed under a Creative Commons Attribution-NonCommercial-NoDerivatives 4.0 International (CC BY-NC-ND 4.0) License. 